\title{
Effect of Process Parameters on Yield of Biofuel Production from Waste Virgin Coconut Oil
}

\author{
Panadda Yotsomnuk and Wanwisa Skolpap* \\ Department of Chemical Engineering, School of Engineering, Thammasat University, Pathumthani 12120, \\ Thailand \\ *E-mail: swanwisa@engr.tu.ac.th
}

\begin{abstract}
This research aimed to determine the influence of process parameters on yields of biofuel production by hydrocracking of waste virgin coconut oil using HZSM-5 zeolite catalyst and to determine statistical relationship of yields of biofuels with the parameters by Pearson's correlation. The various operating parameters in batch reactor were a reaction temperature $\left(350-400^{\circ} \mathrm{C}\right)$, an initial hydrogen pressure (20-40 bar), and a reaction time (1-3 h). The highest yields of gasoline $(6.79 \mathrm{wt} \%)$ and kerosene $(31.38 \mathrm{wt} \%)$ were achieved under a temperature at $400^{\circ} \mathrm{C}$, initial hydrogen pressure at $40 \mathrm{bar}$, and a reaction time of $3 \mathrm{~h}$. The highest yield of diesel of $58.62 \mathrm{wt} \%$ was achieved at a reaction time of $1 \mathrm{~h}$ under temperature $400^{\circ} \mathrm{C}$ and initial hydrogen pressure $40 \mathrm{bar}$. Using Pearson's correlation data analysis, the correlation coefficient between two variables (the yield of biofuel and the operating condition) showed strong dependence of reaction temperature and time on yields of hydrocarbon chains of various length. Yields of shorter hydrocarbon chains such as biogasoline and biokerosene required higher reaction temperature and longer reaction time and vice versa. However, pressure dependence on yields of biofuels was insignificant.
\end{abstract}

Keywords: Hydrocracking, virgin coconut oil, HZSM-5, correlation analysis, biofuel.

ENGINEERING JOURNAL Volume 22 Issue 6

Received 31 January 2018

Accepted 23 August 2018

Published 4 December 2018

Online at http://www.engj.org/

DOI:10.4186/ej.2018.22.6.21 


\section{Introduction}

Due to worldwide environmental concern and the increasing fuel demand, this energy source is being steadily substituted by available renewable sources of liquid fuels such as biofuels, alcohols and vegetable oil. The transformation of vegetable oil to biofuel offers environmental benefits since they are renewable, available, low sulfur and aromatics and bio-degradable. Similar to fossil fuel derived from petroleum, vegetable oil is possible to be thermochemically converted to biofuels such as unfinished gasoline, kerosene, and biodiesel $[1,2]$. There have been many researches about biodiesel production by either the transesterification of vegetable oils and animal fats or the esterification of refined fatty acid esters. The vegetable oils transesterification with short-chain alcohols is carried out by acid or basic catalysts while the esterification of free fatty acids (FFA) presenting in animal fats with alcohols is carried out over heterogeneous acid catalysts [3]. As a result, the products derived from these syntheses are glycerol and esters of the renewable fuel or socalled biodiesel. The selection criteria of feedstock type depend on its domestic availability, cost and quality. Based on the domestic feedstock yield per harvest areas, palm oil and coconuts have the first and second highest potential as precursor for biodiesel production, respectively [4]. Hence, waste virgin coconut oil with high fatty acid content [5], a possible alternative biofuel feedstock, is available at no-to-low price and does not have niche application.

World energy consumed by transportation sector has been substantially increased higher than industry and household [6]. The transportation energy consumption projected for 2020 will be $74 \%$ of total petroleum-based energy. The aviation section depends on fossil fuels contributing to atmospheric pollution. Numerous researches have been conducted to develop sustainable alternatives derived from biomass for aviation [7].

There are several conversion methods of vegetable oils into biofuels, such as thermal cracking, catalytic cracking, and hydrocracking $[8,9,10,11]$. Thermal cracking, a conversion technique of vegetable oil to biofuel, is performed under the condition at high temperature and high pressure in the absence of catalyst. In thermolysis operating at higher temperature, heavy oils consisting higher molecular weight hydrocarbons are transformed to lighter hydrocarbon products with coke formation. The cost of thermal cracking is relatively higher. Moreover, large amount of gas and naphtha produced is relatively low quality due to over cracking $[12,13]$. Therefore, the thermal cracking process has been under development to achieve high-yield middle distillates. Alternatively, catalytic cracking is vegetable oil transformation into biofuel on solid acid catalyst. The catalytic cracking process in the absence of high pressure of hydrogen increases significant amount of desirable olefinic and aromatic compounds containing in biofuels in addition to increase cokedepositing on the catalyst.

Hydrocracking, a combination process of catalytic cracking and hydrogenation, requires high temperature $\left(300-400^{\circ} \mathrm{C}\right)$, high hydrogen pressure, the activity catalyst and more energy for cracking vegetable oils into biofuel in the presence of hydrogen. Properties of the hydrocracking products, i.e. gasoline or kerosene, showed improved oxidation stability and higher cetane numbers [14]. Hydrocracking reaction progress through a dual functional mechanism requires two different types of catalytic sites contributing to catalyze different steps in the reaction system. These bifunctions are the acidic function promoting cracking and isomerization and the metallic function promoting dehydrogenation, hydrogenation and undesirable hydrogenolysis. High-acidity catalyst tends to cause coking, leading to deactivation. In synthesis of optimal hydrocracking catalyst performance, a suitable balance between acid and metal site density has to be maintained.

During hydrocracking, double bonds that contain in triglycerides, become saturated triglycerides at high temperature hydrogen. The resulting free fatty acid and propane occur, when the saturated triglycerides are continuously cracked. The production of straight-chain alkanes can be occurred through hydrodeoxygenation, decarbonylation, or decarboxylation. Oxygen removal in the form of water is achieved by saturation of $\mathrm{C}=\mathrm{O}$, followed by breaking of $\mathrm{C}-\mathrm{O}$ and $\mathrm{C}-\mathrm{C}$ bonds during hydrodeoxygenation [15], while carbon dioxide $\left(\mathrm{CO}_{2}\right)$ and carbon monoxide $(\mathrm{CO})$ are produced during decarboxylation and decarbonylation, respectively [16]. The quantity of resulting products can be transformed into isomers, aromatics, light hydrocarbons and cyclo-compounds that depend on the operating parameters and types of catalysts $[16,17$, 18]. 
Hydrodeoxygenation reaction:

$$
\mathrm{C}_{\mathrm{n}} \mathrm{H}_{2 \mathrm{n}+1} \mathrm{COOH}+3 \mathrm{H}_{2} \longrightarrow \mathrm{C}_{\mathrm{n}+1} \mathrm{H}_{2 \mathrm{n}+4}+2 \mathrm{H}_{2} \mathrm{O}
$$

Decarbonylation reaction:

$$
\mathrm{C}_{\mathrm{n}} \mathrm{H}_{2 \mathrm{n}+1} \mathrm{COOH} \longrightarrow \mathrm{C}_{\mathrm{n}} \mathrm{H}_{2 \mathrm{n}}+\mathrm{H}_{2} \mathrm{O}+\mathrm{CO}
$$

Decarboxylation reaction:

$$
\mathrm{C}_{\mathrm{n}} \mathrm{H}_{2 \mathrm{n}+1} \mathrm{COOH} \longrightarrow \mathrm{C}_{\mathrm{n}} \mathrm{H}_{2 \mathrm{n}+2}+\mathrm{CO}_{2}
$$

The reduction of biofuel production cost and the improvement of product yield can be achieved by developing good selectivity and long lifetime catalysts. In comparison of acidic catalysts, HZSM-5 (Hydrogen Zeolite Socony Mobiles Number 5) showed good performance with the highest yield of gaseous products for cracking palm oil since its pore size is similar to that of triglyceride molecule [19]. The production of biofuels can use HZSM-5 catalyst prepared by impregnation and no impregnation. Budianto et al. [20] studied the catalytic properties of Pt/HZSM- 5 and Pd/HZSM- 5 catalyst on biodiesel production. The Pt/HZSM-5 catalyst gave the highest selectivity and yield of biodiesel achieved at $94.6 \%$ and $67.20 \%$ respectively at temperature of $450^{\circ} \mathrm{C}$. However, the Pt- and Pd- impregnated HZSM- 5 catalysts reduced the production of biokerosene more than that of HZSM-5 at temperature range of 350-550 ${ }^{\circ} \mathrm{C}$. Katikaneni et al. [21] studied the conversion of canola oil over Pt/HZSM- 5 catalyst. They presented that the Pt/HZSM- 5 produced organic liquid product yields of $20-55 \mathrm{wt} \%$ of canola oil while HZSM- 5 produced slightly higher yields of $40-63 \mathrm{wt} \%$ of canola oil. Moreover, improvement of yield and selectivity for the different hydrocracking products was possibly achieved by various modified catalysts with optimal acid sites, pore dimension and crystallinity [22]. Widayat et al. [23] also cracked palm oil over Zn/HZSM-5 catalyst. This research reported that the best result of $23.97 \%$ yield of biodiesel, $2.54 \%$ yield of bio-gasoline and $1.67 \%$ yield of bio-kerosene was obtained at $4 \% \mathrm{Zn}$ concentration. Moreover, the increasing of the operating temperature had significant influence on the yield of biofuels.

This study focused on conversion of waste virgin coconut oil using hydrocracking over HZSM-5 and aimed to develop input-output model for predicting yields of gasoline, biodiesel and kerosene to achieve optimal operating conditions such as reaction temperature, initial hydrogen pressure, and reaction time. Moreover, the strength of a linear relationship between two variables, i.e., the yield of biofuel and the reaction condition, was determined by Pearson's correlation.

\section{Chemicals and Experimental procedure}

\subsection{Chemicals}

Waste virgin coconut oil was obtained from coconut oil extraction process. The zeolite ZSM-5, ammonium powder (commercial grade) was purchased from Alfa Aesar. The silica-to-alumina mole ratio of the zeolite was $80: 1$.

\subsection{Experimental Procedure}

The ammonium-form ZSM- 5 zeolite was dried for overnight and then calcined in airflow at $550^{\circ} \mathrm{C}$ for $5 \mathrm{~h}$. During calcination, the ammonium ions $\left(\mathrm{NH}_{4}^{+}\right)$is decomposed to obtain decationized zeolite or HZSM-5.

\section{Characterization of Catalyst and Method}

\subsection{X-ray Diffraction (XRD)}

X-ray diffraction (Siemens D-500) has been employed to identify and quantify of crystalline phases in the prepared HZSM- 5 before the reaction. The diffractometer was equipped with Ni-filtered $\mathrm{Cu} \mathrm{K}-\alpha$ radiation 
source $(\lambda=1.5418 \AA)$ generating in $30 \mathrm{~mA}$ and $40 \mathrm{kV}$.

The powder samples were scanned from $5^{\circ}$ to $50^{\circ} 2 \theta$ at $2^{\circ} / \mathrm{min}$ with a scanning step of $0.05^{\circ} / \mathrm{step}$. The crystallite size of prepared nanoparticles was estimated by the Scherrer expression as shown in Eq. (1)

$$
D_{\mathrm{p}}=\frac{K \cdot \lambda}{B \cdot \cos \theta}
$$

where $D_{p}$ is crystalline size (nm), $K$ is Scherrer's constant of 0.94 for a spherical crystalline, $B$ is full width at half maximum, $\lambda$ is X-ray wavelength of $1.54 \AA$ and $\theta$ is XRD peak position.

\subsection{Scanning Electron Microscopy (SEM)}

The scanning electron microscopy (Jeol, JSM-7800F) was used for analysis of the morphology and size distribution of sample HZSM- 5 before the reaction. The elements composition and distribution of the sample was analyzed using the mapping technique of SEM/EDX. EDX (JXA 840, Japan) samples were put on a thin carbon film to avoid charging effect during SEM investigation.

\subsection{Gas Chromatography - Mass Spectrometry}

The FFA containing in waste virgin coconut oil was quantified by GC-MS system consisting of an Agilent 7890 gas chromatograph (Agilent Technology, Wilmington, DE, USA) configured with inlet, columns, and flame ionization detector (FID). The capillary column was HP-5MS (30 m, $0.25 \mathrm{~mm}$ i.d., $0.25 \mu \mathrm{m}$ film) (Agilent Technology, Palo Alto, CA, USA). The MS was an Agilent 5977A (Agilent Technology, Wilmington, DE, USA) equipped with an electron ionization (EI) source.

A $2.0 \mu \mathrm{L}$ sample was injected via a split injector with $20: 1$ split at $250{ }^{\circ} \mathrm{C}$ in constant flow mode of $2.0 \mathrm{~mL}$ per minute helium. The oven was set at $50{ }^{\circ} \mathrm{C}$ with heating rate $25^{\circ} \mathrm{C} / \mathrm{min}$ to $200^{\circ} \mathrm{C}$ and then by $3{ }^{\circ} \mathrm{C} / \mathrm{min}$ to $230^{\circ} \mathrm{C}$ for a total run time of $40 \mathrm{~min}$. The $\mathrm{MS}$ transfer line and ion source are set at corresponding temperature of $230{ }^{\circ} \mathrm{C}$ and $150{ }^{\circ} \mathrm{C}$ with fixed electron energy at $70 \mathrm{eV}$. The mass spectral range was $46-500 \mathrm{~m} / \mathrm{z}$ with a scan rate of $4.4 \mathrm{scan} / \mathrm{s}$.

\subsection{Hydrocracking Process}

The hydrocracking experiments of waste virgin coconut oil were performed using a $200 \mathrm{ml}$ batch reactor at stirring speed of $350 \mathrm{rpm}$. The operative limits of the reactor were $200 \mathrm{bar}$ and $400^{\circ} \mathrm{C}$. Prior to the experiments, gas leakage testing was conducted by loading hydrogen gas up to 70 bar at room temperature and kept for $30 \mathrm{~min}$. After that, HZSM-5 catalyst $(1 \mathrm{~g})$ was introduced into the reactor and activated with hydrogen flow at $400^{\circ} \mathrm{C}$ and $50 \mathrm{bar}$ for $4 \mathrm{~h}$. Then $100 \mathrm{ml}$ waste coconut oil was introduced into the reactor. The experiments were performed over a range of conditions with temperature from 350 to $400 \pm 3^{\circ} \mathrm{C}$, initial hydrogen pressure from 20 to $40 \mathrm{bar}$ and reaction time from 1 to $3 \mathrm{~h}$.

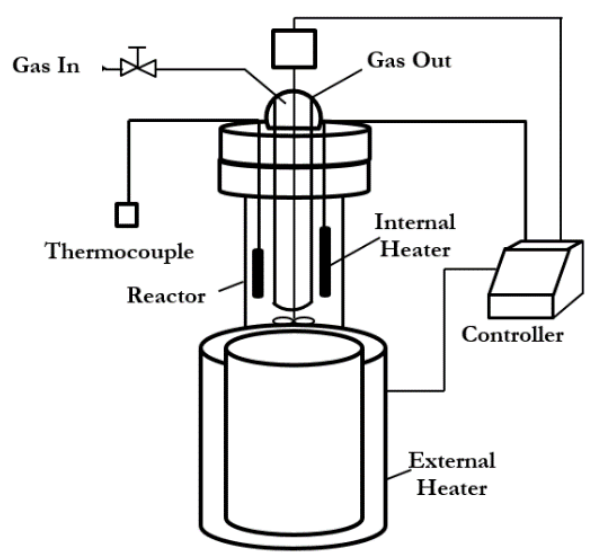

Fig. 1. Batch reactor apparatus. 
The batch reactor was heated up until the final temperature was reached, allowing the reaction to progress. After the reaction was completed, the built-in cooling coil was used to cool the reactor back to ambient temperature. The liquid products of hydrocracking were collected while gaseous products were not collected for analysis. The products were filtrated to separate the catalyst. The hydrocracked total liquid product was then analyzed by distillation.

The catalytic performance was calculated through the conversion, yield and selectivity of produced biofuel as expressed in Eqs. (2), (3) and (4), respectively.

$$
\begin{gathered}
\text { Conversion }(\mathrm{wt} \%)=\frac{\text { initial feedstock }(\mathrm{g}) \text {-residue }\left(>340^{\circ} \mathrm{C}\right) \text { after cracking }}{\text { initial feedstock }(\mathrm{g})} \times 100 \% \\
\text { Yield }(\mathrm{wt} \%)=\frac{\text { weight of fractional distillation of liquid products }(\mathrm{g})}{\text { initial feed stock }(\mathrm{g})} \times 100 \% \\
\text { Selectivity }(\mathrm{wt} \%)=\frac{\text { weight of target product }(\mathrm{g})}{\text { weight of liquid product }(\mathrm{g})} \times 100 \%
\end{gathered}
$$

where initial feedstock and residue $\left(>340^{\circ} \mathrm{C}\right)$ after cracking weights of the feed and unconverted feedstock, respectively.

The product yields were calculated from the total distillate product. The compositions of hydrocracking liquid product were separated into many different products by their various boiling temperature. The boiling points of gasoline, kerosene and diesel were in the range of $40-160^{\circ} \mathrm{C}, 160-270^{\circ} \mathrm{C}$ and $270-360^{\circ} \mathrm{C}$, respectively. Moreover, long chain hydrocarbon molecule with boiling point $>360^{\circ} \mathrm{C}$, the unconverted waste coconut oil, cannot be produced liquid biofuel.

\subsection{Statistical Analysis}

Pearson's correlation describes the strength of the relationship between two variables representing by $r$ (correlation coefficient) if there is a linear relationship between these two quantitative variables. In this study, the relationship between the yield of biofuel $\left(Y_{\text {gasoline, }}, Y_{\text {kerssene }}\right.$, and $\left.Y_{\text {diesel }}\right)$ and reaction condition was described by Pearson's correlation. Pearson's correlation coefficient $(r)$ was carried out using the SPSS 16.0 software for Windows (SPSS, Inc., Chicago, IL, USA) to generate Pearson correlation at 95\% confidence interval ( $p<$ $0.05)$. At $p$-value less than the significance level of 0.05 , the null hypothesis on a significant non-linear relationship between the two variables is rejected since $r$ is significantly different from zero.

\section{Results and Discussion}

\subsection{X-ray Diffraction (XRD)}

The X-ray diffraction pattern of HZSM-5 is illustrated in Figure 2. The XRD peak position and intensity of H-ZSM-5 catalyst are consistent with the formerly revealed pattern [24]. The XRD characteristic peaks of HZSM-5 at the $2 \theta$ values of $7.92^{\circ}, 8.32^{\circ}, 22.68^{\circ}, 23.13^{\circ}, 23.15^{\circ}$ and $24.41^{\circ}$ indicate HZSM-5of MFI framework type. The average crystalline dimension of the obtained HZSM-5 using Eq. (1) was $18.34 \mathrm{~nm}$. 


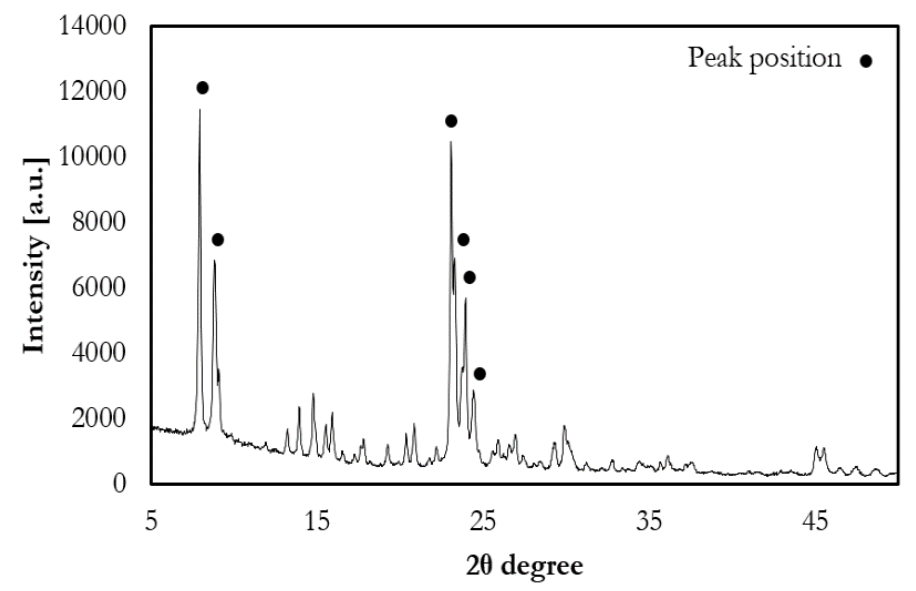

Fig. 2. XRD peaks of catalyst HZSM-5.

\subsection{Scanning Electron Microscopy (SEM)}

Scanning electron microscopy (SEM) equipped with energy-dispersive X-ray analysis spectroscopy (EDX) was used to study the surface morphology and to determine the Si/Al composition of HZSM-5. The SEM images of HZSM-5 and ZSM-5 were taken at 10000X magnification to observe their surface morphology in Figs. 3(a) and 3(b). The SEM images of H-ZSM-5 and ZSM-5 were similar. The obtained ZSM-5 zeolite has shapes close to cubic crystals with an average particle size $7.52 \mathrm{~nm}$ measured by ImageJ Program which is 1.8-fold smaller than the average crystalline size measured by XRD. However, the diameter variation is insignificant due to nanoscale measurement. Energy-dispersive X-ray analysis spectroscopy (EDX) shows that the HZSM-5 structure consisted of $\mathrm{Si}$ and $\mathrm{Al}$ in ratio of 44.45:1 as shown in Fig. 4.

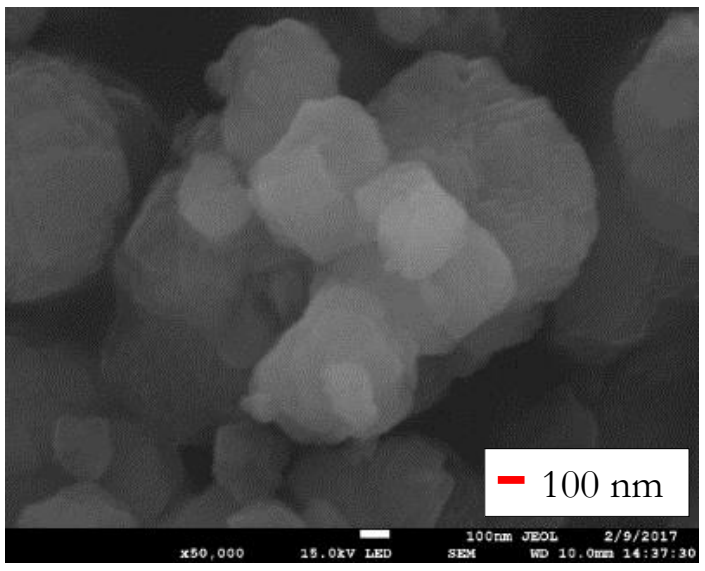

(a)

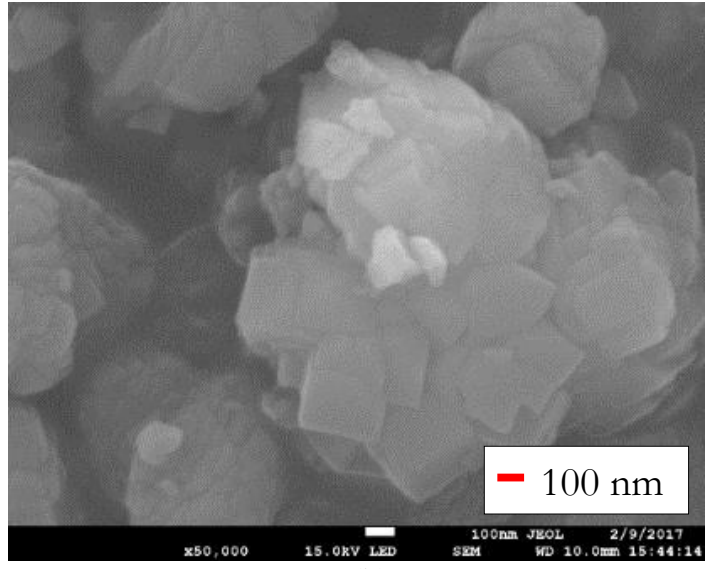

(b)

Fig. 3. Results of SEM images: (a) HZSM-5; (b) ZSM-5. 


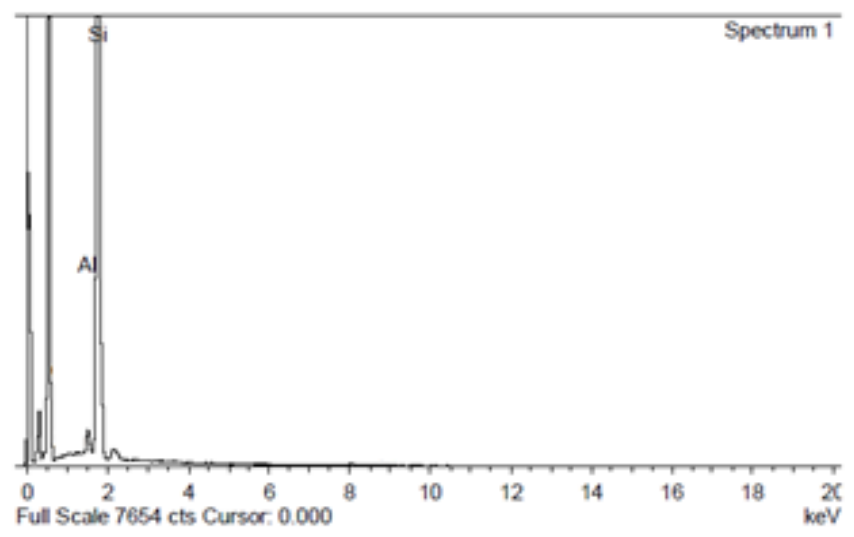

Fig. 4. EDAX Spectrum of HZSM-5.

\subsection{Waste Virgin Coconut Oil Composition}

The composition analysis of waste virgin coconut oil using gas chromatography-mass spectroscopy (GC-MS) is presented in Table 1. The constituent of waste virgin coconut oil is the medium-chain triglycerides in the form of fatty acids of chain length C8:0 to C14:0 and the main constituent of waste virgin coconut oil is saturated fatty acid (caprylic acid, capric acid, luaric acid, and myristic acid). The rich composition in waste virgin coconut oil is lauric acid (C12:0) of $58.79 \mathrm{wt} \%$. In agreement with the previous work [25], the proportion of fatty acids also is rich in the range of lauric acid of 45.1-53.2 $\mathrm{wt} \%$.

Table 1. Composition of the waste virgin coconut oil.

\begin{tabular}{|l|l|l|}
\hline \multirow{2}{*}{ Organic acids } & Waste virgin coconut oil & Previous work [25] \\
\cline { 2 - 3 } & Composition (wt $\%)$ & \\
\hline C6:0 & ND & ND-0.7 \\
C8:0 & 15.65 & $4.6-10.0$ \\
C10:0 & 11.19 & $5.0-8.0$ \\
C12:0 & 58.79 & $45.1-53.2$ \\
C14:0 & 14.38 & $16.8-21.0$ \\
C16:0 & ND & $7.5-10.2$ \\
C18:0 & ND & $2.0-4.0$ \\
C18:1 & ND & $5.0-10.0$ \\
C18:2 & ND & $1.0-2.5$ \\
C18:3 & ND & ND-0.2 \\
C20:0 & ND & ND-0.2 \\
C20:1 & ND & ND-0.2 \\
C20:2-C24:1 & ND & ND \\
\hline ND not detected
\end{tabular}

\subsection{Effect of Parameter Condition on Hydrocracking}

\subsubsection{Initial hydrogen pressure}

Since the hydrogen pressure is one of the major limiting parameters in hydroprocessing process (hydrocracking and hydrotreating), the influence of the initial hydrogen pressure is studied. A variation of initial hydrogen pressure, i.e. 20,30, and $40 \mathrm{bar}$, of the waste virgin coconut oil hydrocracking over $1 \mathrm{~g}$ of HZSM-5 was performed under a reaction time of $400^{\circ} \mathrm{C}$ and a reaction time of $1 \mathrm{~h}$. 
Table 2. The hydrocracking results of waste virgin coconut oil with a variation of initial hydrogen pressure.

\begin{tabular}{|l|l|l|l|l|l|l|l|l|l|}
\hline \multirow{2}{*}{ Sample } & \multicolumn{4}{|l|}{ Yield of liquid product $(\mathrm{wt} \%)$} & \multicolumn{3}{|l|}{ Selectivity $(\mathrm{wt} \%)$} & \multirow{2}{*}{$\begin{array}{l}\text { Conversion } \\
(\mathrm{wt} \%)\end{array}$} \\
\cline { 2 - 10 } & gasoline & kerosene & diesel & residue & gasoline & kerosene & diesel & residue & \\
\hline A-1 & 1.36 & 19.04 & 43.5 & 20.40 & 1.61 & 22.59 & 51.60 & 24.20 & 63.90 \\
A-2 & 1.70 & 19.75 & 42.81 & 19.60 & 2.02 & 23.55 & 51.05 & 23.37 & 64.25 \\
A-3 & 2.72 & 21.86 & 41.96 & 17.40 & 3.24 & 26.05 & 49.99 & 20.73 & 66.54 \\
\hline
\end{tabular}

${ }^{*} \mathrm{~A}-1: \mathrm{T}=400^{\circ} \mathrm{C} ; P=20$ bar; $t=1 \mathrm{~h}$

A-2: $T=400^{\circ} \mathrm{C} ; P=30 \mathrm{bar} ; t=1 \mathrm{~h}$

A-3: $T=400^{\circ} \mathrm{C} ; P=40 \mathrm{bar} ; t=1 \mathrm{~h}$

With the increase of pressure from 20 to 40 bar, waste virgin coconut oil conversion insignificantly reduced by $0.04 \%$ as shown in Table 2 . At low initial hydrogen pressure of 20 bar, only $63.90 \mathrm{wt} \%$ of the waste virgin coconut oil was transformed to liquid biofuel. When increasing an initial hydrogen pressure from 20 to 40 bar, the yield and selectivity of biofuels (gasoline, kerosene, and diesel) are not affected significantly. This is consistent with the study of Sotelo-Boyás et al. [26] that the yield of diesel is not significant change by pressure. . It may be attributed that hydrodeoxygenation, saturation and heteroatom removal are favored at higher pressure producing more water as well $[9,26]$; which in turn may deactivate the catalyst causing the reduction of the catalyst effectiveness for hydrocracking process.

\subsubsection{Reaction temperature}

The reaction temperature, i.e. $350^{\circ} \mathrm{C}, 375^{\circ} \mathrm{C}$ and $400^{\circ} \mathrm{C}$, affected yields of the hydrocracked products of waste virgin coconut oil was investigated. The experiments were performed under initial hydrogen pressure of 40 bar and a reaction time of $1 \mathrm{~h}$ over $1 \mathrm{~g}$ of HZSM-5 (powder form).

Table 3. The hydrocracking results of waste virgin coconut oil with a variation of temperature.

\begin{tabular}{|l|l|l|l|l|l|l|l|l|l|}
\hline \multirow{2}{*}{ Sample } & \multicolumn{4}{|c|}{ Yield of liquid product $(\mathrm{wt} \%)$} & \multicolumn{3}{|l|}{ Selectivity $(\mathrm{wt} \%)$} & \multicolumn{2}{|l|}{$\begin{array}{l}\text { Conversion } \\
\text { (\%wt) }\end{array}$} \\
\cline { 2 - 10 } & gasoline & kerosene & diesel & residue & gasoline & kerosene & diesel & residue & \\
\hline B-1 & 0.35 & 10.58 & 58.62 & 11.80 & 0.43 & 13.00 & 72.06 & 14.51 & 69.55 \\
B-2 & 0.57 & 14.11 & 52.45 & 15.60 & 0.69 & 17.05 & 63.40 & 18.86 & 67.13 \\
A-3 & 2.72 & 21.86 & 41.96 & 17.40 & 3.24 & 26.05 & 49.99 & 20.73 & 66.54 \\
\hline
\end{tabular}

${ }^{*} \mathrm{~B}-1$ : reaction temperature $(T) 350^{\circ} \mathrm{C}$; initial pressure $(P) 40$ bar; reaction time $(t) 1 \mathrm{~h}$

B-2: $T=375^{\circ} \mathrm{C} ; P=40$ bar; $t=1 \mathrm{~h}$

A-3: $T=400^{\circ} \mathrm{C} ; P=40$ bar; $t=1 \mathrm{~h}$

Waste virgin coconut oil conversion to liquid biofuel calculated using Eq. (1) was found to be temperature dependent. Amongst three liquid fractions, the major produced petroleum-like fraction was diesel. Waste virgin coconut oil conversion decreased with increasing temperature. When temperature increases from 350 to $400^{\circ} \mathrm{C}$, the conversion of liquid biofuel slightly decreased from $69.55 \mathrm{wt} \%$ to $66.54 \mathrm{wt} \%$ as shown in Table 3. This may be attributed that the prepared HZSM-5 contains only acidic sites lacking metallic sites. 
Consequently, disproportion between hydrogenation and acid functions causes a variation of apparent reaction pathway of the observable compounds in the system [27].

Increasing the reaction temperature up to $400^{\circ} \mathrm{C}$, the $Y_{\text {kerossene }}$ and $Y_{\text {gasoline }}$ were increased by a corresponding factor of 1.1 and 6.75 while the $Y_{\text {diesel }}$ was decreased by a factor of 0.28 . It is consistent to the studies of that the most suitable temperature for gasoline and kerosene production was higher than $350^{\circ} \mathrm{C}[20,26]$. Additionally, Widayat et al. [23] found that the yield of biofuels producted by catalytic cracking method using Zn/HZSM-5 catalyst was positively affected by high temperature cracking.

\subsubsection{Reaction period}

The range of reaction period between 1 to $3 \mathrm{~h}$ of hydrocracking process was investigated under a reaction temperature of $400^{\circ} \mathrm{C}$ and initial hydrogen pressure at 40 bar over $1 \mathrm{~g}$ of HZSM-5.

Table 4. The hydrocracking results of waste virgin coconut oil with a variation of reaction period.

\begin{tabular}{|l|l|l|l|l|l|l|l|l|l|}
\hline \multirow{2}{*}{ Sample } & \multicolumn{4}{|l|}{ Yield of liquid product $(\mathrm{wt} \%)$} & \multicolumn{3}{l|}{ Selectivity $(\mathrm{wt} \%)$} & \multirow{2}{*}{$\begin{array}{l}\text { Conversion } \\
(\mathrm{wt} \%)\end{array}$} \\
\cline { 2 - 10 } & gasoline & kerosene & diesel & residue & gasoline & kerosene & diesel & residue & \\
\hline A-3 & 2.72 & 21.86 & 41.96 & 17.40 & 3.24 & 26.05 & 49.99 & 20.73 & 66.54 \\
C-2 & 3.06 & 19.39 & 43.20 & 18.40 & 3.63 & 23.08 & 51.40 & 21.89 & 65.64 \\
C-3 & 6.79 & 31.38 & 27.77 & 20.40 & 7.86 & 36.35 & 32.16 & 23.63 & 65.94 \\
\hline
\end{tabular}

${ }^{*} \mathrm{~A}-3: \mathrm{T}=400^{\circ} \mathrm{C} ; P=40 \mathrm{bar} ; t=1 \mathrm{~h}$

$\mathrm{C}-2: \mathrm{T}=400^{\circ} \mathrm{C} ; P=40 \mathrm{bar} ; t=2 \mathrm{~h}$

C-3: $T=400^{\circ} \mathrm{C} ; P=40 \mathrm{bar} ; t=3 \mathrm{~h}$

As shown in Table 4 the reaction time of $2 \mathrm{~h}$ was the most suitable hydrocracking time period for diesel production while that of $3 \mathrm{~h}$ was the most suitable cracking time period for kerosene and gasoline production. At reaction time of $1 \mathrm{~h}, 66.54 \mathrm{wt} \%$ of the waste virgin coconut oil was transformed to liquid biofuel. Upon decreasing the reaction time to $2 \mathrm{~h}$ and $3 \mathrm{~h}$, the liquid produce fractions was $65.64 \mathrm{wt} \%$ and $65.94 \mathrm{wt} \%$, respectively. It was pronounced that short time for hydrocracking was required for heavy fraction product, particularly diesel. After the hydrocracking was progressed, diesel was further reduced to light fraction products such as kerosene and gasoline.

As increasing the reaction time from $1 \mathrm{~h}$ to $3 \mathrm{~h}, Y_{\text {diesel }}$ was dramatically decreased from $41.96 \mathrm{wt} \%$ to 27.77 $\mathrm{wt} \%$, respectively at $3 \mathrm{~h}$ at a constant reaction temperature of $400^{\circ} \mathrm{C}$ and initial hydrogen pressure of $40 \mathrm{bar}$. However, $Y_{\text {kerssene }}$ and $Y_{\text {gassiline }}$ increased with the reaction time. The $Y_{\text {kerssene }}$ and $Y_{\text {gassiline }}$ was increased from 21.86 to $31.38 \mathrm{wt} \%$ and 2.72 to $6.79 \mathrm{wt} \%$, respectively. Therefore, $2 \mathrm{~h}$ and $3 \mathrm{~h}$ reaction times are the most suitable temperature for diesel and kerosene production, respectively. The increased reaction period results in undergoing further cracking to lighter produce fraction and reduces the diesel produce fraction. Moreover, longer reaction time can cause evaporation of light fraction to become gas phase [28].

\subsection{Data Analysis from the Input-Output Model}

A quantitative predictive linear model based on can be determined by calculating input-output coefficients of values of input (reaction temperature, initial hydrogen pressure, and reaction period) and output (yields of gasoline, kerosene and diesel). The set of experimental data of hydrocracking of waste virgin coconut oil for producing liquid biofuel was modeled to estimate input-output coefficients as follows:

$$
\text { The input-output model was proposed as } \mathbf{Z}=\alpha+\beta \boldsymbol{P}+\gamma \boldsymbol{T}+\delta \boldsymbol{t}
$$

where $\mathbf{Z}=7 \mathrm{x} 1$ vector of liquid biofuel yields $\{$ Yield $\}$ under all seven conditions, 
$\boldsymbol{P}=$ initial hydrogen pressure, $\{20,30,40\}$ bar,

$\boldsymbol{T}=$ reaction temperature, $\{350,375,400\}{ }^{\circ} \mathrm{C}$,

$\boldsymbol{t}=$ reaction period, $\{1,2,3\} \mathrm{h}$

It can be written in matrix form as follows:

$$
\mathbf{Z}=\mathbf{A B} \text { or } \mathbf{B}=\mathbf{A}^{-1} \mathbf{Z}
$$

where $\mathbf{A}=7 \times 4$ matrix of the total experimental conditions,

$\mathbf{B}=4 \times 1$ vector of model coefficients, $[\alpha \beta \gamma \delta]^{\mathrm{T}}$.

The input-output model coefficients were determined by solving a linear matrix equation with Matlab ${ }^{\circledR}$ (Mathworks, MA, USA) as presented in Table 5.

Table 5. The calculated input-output coefficients.

\begin{tabular}{|ll|ll|ll|ll|}
\hline$\alpha$ & & $\beta$ & & $\gamma$ & \multicolumn{2}{|l|}{} \\
\hline$\alpha_{1}$ & -16.2160 & $\beta_{1}$ & 0.0298 & $\gamma_{1}$ & 0.0371 & $\delta_{1}$ & 2.1460 \\
$\alpha_{2}$ & -58.5420 & $\beta_{2}$ & 0.0044 & $\gamma_{2}$ & 0.1822 & $\delta_{2}$ & 4.8200 \\
$\alpha_{3}$ & 163.2290 & $\beta_{3}$ & 0.0800 & $\gamma_{3}$ & -0.2870 & $\delta_{3}$ & -7.0143 \\
\hline
\end{tabular}

The proposed input-output predicting models were expressed as:

$$
\begin{gathered}
Y_{\text {gasoline }}=-16.2160+0.0298 P+0.0371 T+2.1460 t \\
Y_{\text {kerrsene }}=-58.5420+0.0044 P+0.1822 T+4.8200 t \\
Y_{\text {diesel }}=163.2290+0.0800 P-0.2870 T-7.0143 t
\end{gathered}
$$

Equations (7)-(9) were plotted as shown in Figs. 2-4.

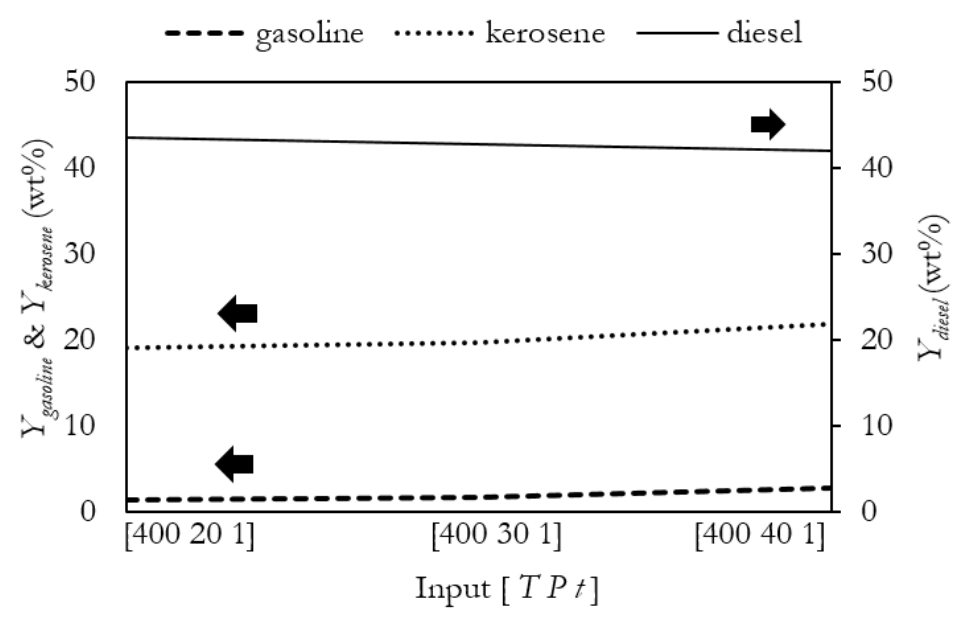

(a) 


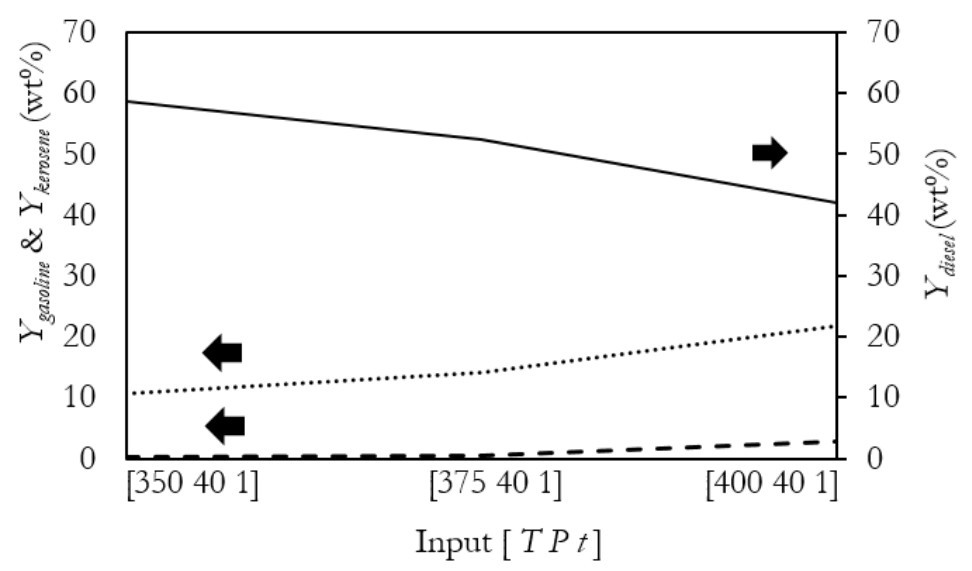

(b)

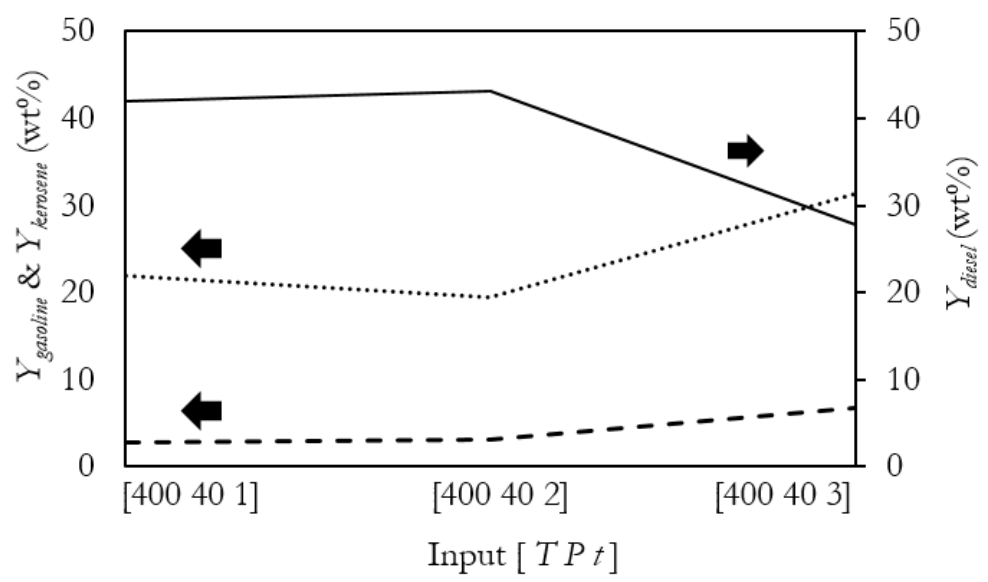

(c)

Fig. 5. The input-output correlation of effect of parameter conditions; (a) initial hydrogen pressure, $P$; (b) reaction temperature, $T$; $(\mathrm{c})$ and reaction period, $t$.

A positive value of $\alpha$ represents favorable effect on the yield of diesel ( $\left.Y_{\text {diesel }}\right)$ while a negative value of $\alpha$ represents unfavorable effect on the yield of kerosene $\left(Y_{\text {kerssene }}\right)$ and the yield of gasoline $\left(Y_{\text {gasoline }}\right)$. The increase of initial hydrogen pressure has no significant effect on $Y_{\text {kerossene, }} Y_{\text {gassoline }}$ and $Y_{\text {diesel }}$ as shown in Fig. 5a. This agrees with the observation of Sotelo-Boyás et al. [26] that the yield of diesel is hydrogen pressure independent. The increase of temperature and a reaction time has insignificantly adverse effect on $Y_{\text {diese }}$ as shown in corresponding Figs. 5b and 5c. Moreover, the increase of reaction time and reaction temperature has positive effect on $Y_{\text {gassoline }}$ and $Y_{\text {kerssene }}$ as shown in Fig. 5b. At the increase of temperature and reaction period, the hydrocarbon fraction in the range of diesel can be broken down into smaller molecules, such as gasoline and kerosene. This is consistent with the observation of Satyarthi et al. [29] that the increase of cracking temperatures is favourable to produce lighter hydrocarbon products.

\subsection{Statistical Data Analysis}

\subsubsection{Accuracy of models used in predicting liquid biofuel yields}

The coefficient of determination that gave an estimated $R^{2}$ values of yield prediction models of gasoline, kerosene, and diesel was 0.9227, 0.8605, and 0.9133, respectively as shown in Figs. 6(a)-6(c). This shows better fit between modeled and observed data of $Y_{\text {gassine }}$ and $Y_{\text {diesel }}$ than that of $Y_{\text {kerssene }}$. 


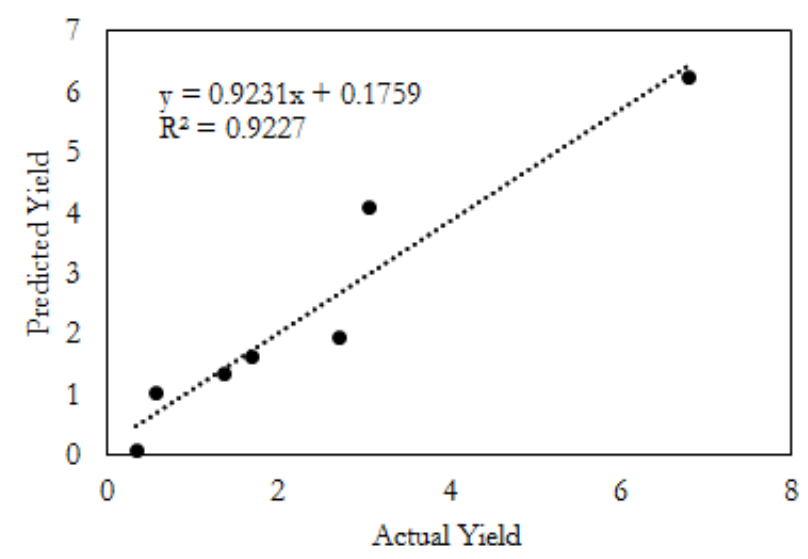

(a)

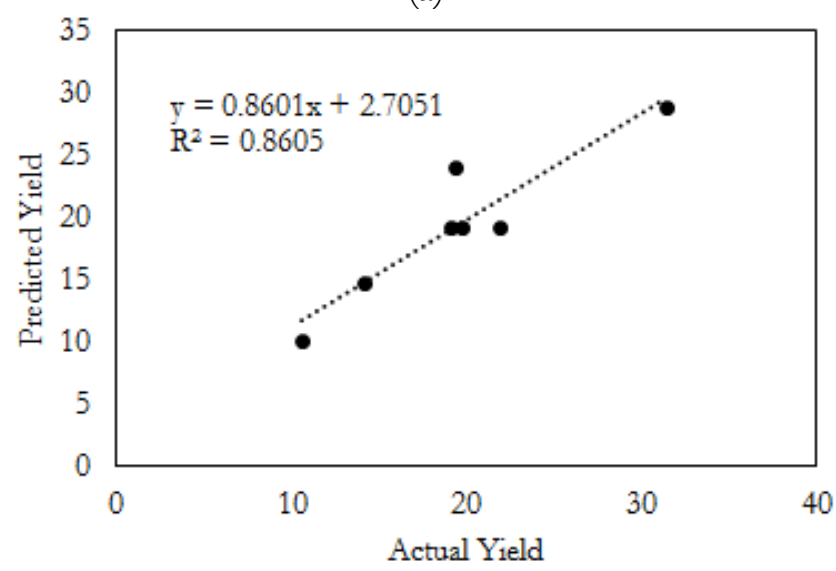

(b)

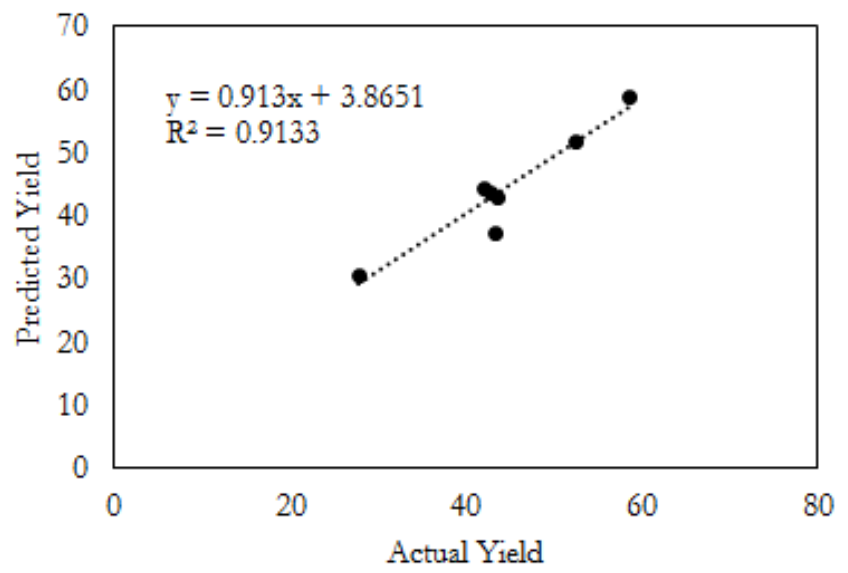

(c)

Fig. 6. Correlation between actual and predicted yield of (a) gasoline, (b) kerosene, and (c) diesel.

\subsubsection{Data analysis - Pearson's correlation}

Pearson's correlation is a statistical measure of the association stength between two variables. Pearson's correlation ranges between +1 and -1 where +1 shows a perfect relationship, -1 shows adverse relationship and 0 indicates no associaton between two variables. An $r$ value indicates strength in relationship between variables as follows: $0 \leq r \leq 0.29$, weak; $0.30 \leq r \leq 0.39$, moderate; $0.40 \leq r \leq 0.69$, strong; and $r>0.70$, very strong. 
Table 6. Pearson's correlation coefficients of yields of liquid biofuel with initial hydrogen pressure $(P)$, reaction temperature $(T)$, and reaction time $(t)$.

\begin{tabular}{|cl|lll|}
\hline \multicolumn{2}{|l|}{ Pearson's correlation } & $P$ & $T$ & $t$ \\
\hline$Y_{\text {gassoline }}$ & Correlation coefficient & 0.258 & 0.561 & $0.921^{* *}$ \\
& Significance (2-tailed) & 0.576 & 0.19 & 0.003 \\
\hline$Y_{\text {kerssene }}$ & Correlation coefficient & 0.016 & 0.749 & $0.773^{*}$ \\
& Significance (2-tailed) & 0.972 & 0.053 & 0.042 \\
\hline$Y_{\text {diesel }}$ & Correlation coefficient & 0.07 & $-0.809^{*}$ & $-0.755^{*}$ \\
& Significance (2-tailed) & 0.882 & 0.028 & 0.05 \\
\hline
\end{tabular}

${ }^{*} p$-value of 0.05 (2-tailed).

** $p$-value of 0.01 (2-tailed).

The Pearson's correlation in Table 6 shows very strong negative relationship of the $Y_{\text {diese }}$ with reaction temperature $(T)$ and time $(t)$ with corresponding $r$ values of -0.809 and -0.755 . On the other hand, the $Y_{\text {kerssene }}$ shows very strong positive relationship with $T$ and $t$ with corresponding $r$ values of 0.749 and 0.773 . The $Y_{\text {gassoline }}$ shows very strong positive relationship with $t$ with $r$ value of 0.921 while this shows strong positive relationship with $T$ with $r$ value of and 0.561 . It showed that the temperature mainly affected the thermal cracking of long chain hydrocarbon into light products, and further cracking resulting in a light hydrocarbon product with increasing the reaction time [13, 17]. Marlinda et al. [30] also reported that the increase of temperature improves the activity of hydrocracking process and facilitates cleavage a heavy hydrocarbon into lighter hydrocarbon products. At higher temperature and longer hydrocracking reaction time, hydrodeoxygenation (R.1) was favored resulting in the improvement of yield of liquid products [20]. As shown in Table 2, the $Y_{\text {diese }}$ was dramatically decreased with the increase of temperature, probably caused by the continued cracking of the long chain hydrocarbons to light products such as kerosene and gasoline. At temperatures above $350^{\circ} \mathrm{C}$, the capacity of cracking of $n$-paraffins and iso-paraffins in the boiling range of bio-diesel was enhanced; which in turn, the yield of light product fractions as gasoline and kerosene was increased [26].

The yield of diesel $\left(Y_{\text {diesele }}\right)$ and that of kerosene $\left(Y_{\text {kerosene }}\right)$ have no relationship with initial hydrogen pressure $(P)$ indicating $P$ independence of $Y_{\text {diesel }}$ and $Y_{\text {eerssene }}$ as shown in Table 6. Moreover, the $Y_{\text {gassline }}$ has a weak positive relationship with $P$ indicating $P$ dependence of the $Y_{\text {gassline }}$. Hydrogen pressure is necessary to avoid deactivation of the catalyst $[31,32]$. Higher pressure would enhance the absorbed hydrogen on the surface active sites promoting hydrodeoxygenation and it produces more water, which may deactivate the catalyst. At the increase of the initial hydrogen pressure, the improvement of $Y_{\text {gassline }}$ was slightly more noticeable than that of $Y_{\text {kerssene }}$ and $Y_{\text {diesel. }}$ It was consisitent with the study of Heriyanto et al.[33] that the increase of hydrogen pressure from 30 to 60 bar causes a neglegible change in $Y_{\text {diesel }}$.

\section{Conclusions}

The hydrocracking reactions using zeolite (HZSM-5) catalysts under high temperature were more favorable to production of kerosene and gasoline than that of diesel. Longer time for hydrocracking was required for lighter fraction product such as gasoline and kerosene. The Pearson's correlation coefficients show strong dependence of reaction temperature and time on $Y_{\text {gassoline }}$ and $Y_{\text {kerosene }}$ while these show strong adverse relationship of $Y_{\text {dieses }}$ Pressure dependence on yields of biofuels is insignificant. Under temperature of $350^{\circ} \mathrm{C}$, initial hydrogen pressure of $40 \mathrm{bar}$ and reaction period of $1 \mathrm{~h}$, the hydrocracking reactions using the prepared HZSM- 5 catalyst gave the highest yield and selectivity of diesel of $58.62 \mathrm{wt} \%$ and $72.06 \mathrm{wt} \%$, respectively. The highest yield of kerosene $(31.38 \mathrm{wt} \%)$ and the selectivity of kerosene $(36.35 \mathrm{wt} \%)$ were achieved at temperature of $400^{\circ} \mathrm{C}$, initial hydrogen pressure of 40 bar and reaction period of $3 \mathrm{~h}$. The HZSM- 5 catalyst is recommended for cracking of waste virgin coconut oil to biofuel containing mainly diesel and kerosene. 


\section{Acknowledgement}

The authors are grateful to the Faculty of Engineering, Thammasat University, Thailand for their financial support.

\section{Nomenclature}

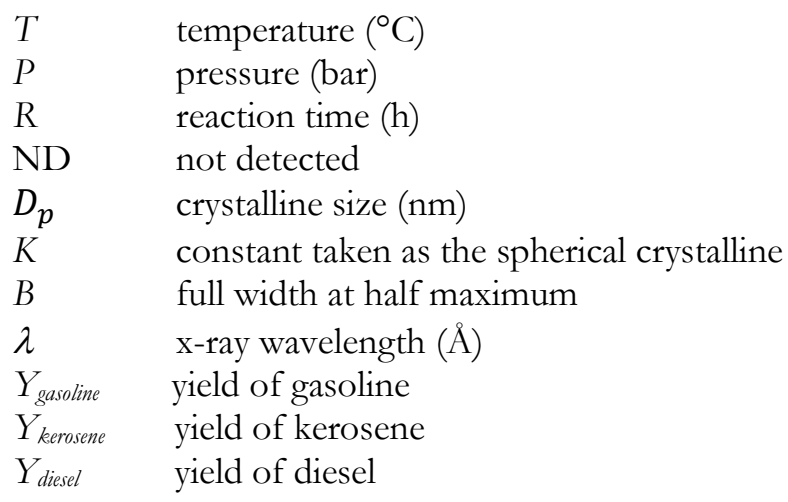

\section{References}

[1] T. Kimura, H. Imai, X. Li, K. Sakashita, S. Asaoka, and S.S. Al-Khattaf, "Hydroconversion of

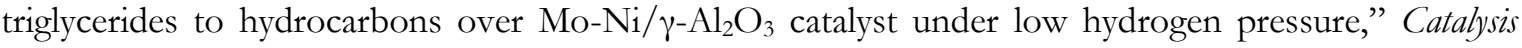
Letters, vol. 1, no. 143, pp. 1175-1181, 2016.

[2] C. H. Zandonai, P. H. Yassue-Cordeiro, S. B. Castellã-Pergher, M. H. N. O. Scaliante, and N. R. C. Fernandes-Machado, "Production of petroleum-like synthetic fuel by hydrocracking of crude soybean oil over ZSM5 zeolite-Improvement of catalyst lifetime by ion exchange," Fuel, vol. 1, no. 172, pp. 228-237, 2016.

[3] S. Kappally, A. Shirwaikar, and A. Shirwaikar, "Coconut oil—A review of potential application," Drugs and Medicines, vol. 7, no. 2, pp. 34-41, 2015.

[4] P. Nimmanterdwong, B. Chalermsinsuwan, and P. Piumsomboon, "Energy evaluation of biofuel production in Thailand from different feedstocks," Ecological Engineering, vol. 74, pp. 423-437, 2015.

[5] J. F. G. Oliveira, I. L. Lucena, R. M. Alves Saboya, M. L. Rodrigues, A. E. B. Torres, F. A. Narciso Fernandes, C. L. Cavalcante, Jr., and E. J. S. Parente, Jr., "Biodiesel production from waste coconut oil by esterification with ethanol: The effect of water removal by adsorption," Renewable Energy, vol. 35, pp. 2581-2584, 2010.

[6] N. Yilmaz and A. Atmanli, "Sustainable alternative fuels in aviation," Energy, vol. 140, pp. 1378-1386, 2017.

[7] U. Neuling and M. Kaltschmitt, "Techno-economic and environmental analysis of aviation biofuels," Fuel Processing Technology, vol. 171, pp. 54-69, 2018.

[8] M. Anand, S. A. Farooqui, R. Kumar, R. Joshi, R. Kumar, M. G. Sibi, H. Singh, and A. K. Sinha, "Optimizing renewable oil hydrocracking conditions for aviation bio-kerosene production," Fuel Processing Technology, vol. 1, no. 151, pp. 50-58, 2016.

[9] W. Charusiri and T. Vitidsant, "Kinetic study of used vegetable oil to liquid fuels over sulfated zirconia," Energy Fuels, vol. 19, no. 5, pp. 1783-1789, 2005.

[10] R. Rasyid, A. Prihartantyo, M. Mahfud, and A. Roesyadi, "Hydrocracking of Calophyllum inophyllum oil with non-sulfide CoMo catalysts," Bulletin of Chemical Reaction Engineeringe Catalysts, vol. 1, no. 10, pp. 61-69, 2015.

[11] H. Wilczura-Wachnik, "Catalytic cracking of hydrocarbons," University of Warsaw, Faculty of Chemistry, 2013.

[12] I. Salim, W. Trisunaryanti, T. Triyono, and Y. Arryanto, "Hydrocracking of coconut oil into gasoline fraction using NI/modified natural zeolite catalyst," International Journal of ChemTech Research, vol. 9, no. 4, pp. 492-500, 2016.

[13] D. Verma, B. S. Rana, R. Kumar, M. G. Sibi, and A. K. Sinha, "Diesel and aviation kerosene with desired aromatics from hydroprocessing of jatropha oil over hydrogenation catalysts supported on hierarchical mesoporous SAPO-11," Applied Catalysis, vol. 490, pp. 108-116, 2015. 
[14] C. Liu, J. Liu, G. Zhou, W. Tian, and L. Rong, "A cleaner process for hydrocracking of jatropha oil into green diesel," Journal of the Taiwan Institute of Chemical Engineers, vol. 44, no. 2, pp. 221-227, 2012.

[15] S. Bezergianni and V. Dagonikou, "Effect of $\mathrm{CO}_{2}$ on catalytic hydrotreatment of gas-oil," Canadian Journal of Chemical Engineering, vol. 93, no. 6, pp. 1017-1023, 2015.

[16] M. Mohammad, T. K. Hari, Z. Yaakob, Y. C. Sharma, and K. Sopian, "Overview on the production of paraffin based-biofuels via catalytic hydrodeoxygenation," Renewable and Sustainable Energy Reviews, vol. 22, pp. 121-132, 2013.

[17] S. Kim, J. Han, H. Lee, T. Yum, Y. Kim, and J. Kim, "Production of renewable diesel via catalytic deoxygenation of natural triglycerides: Comprehensive understanding of reaction intermediates and hydrocarbons," Applied Energy, vol. 116, pp. 199-205, 2014.

[18] B. Veriansyah, J. Han, S. Kim, S. Hong, Y. Kim, J. Lim, and J. Kim, "Production of renewable diesel by hydroprocesing of soybean oil: Effect of catalysts," Fuel, vol. 94, no. 1, pp. 578-585, 2012.

[19] F. A Twaiq, N. A. M Zabidi, and S. Bhatia, "Catalytic conversion of palm oil to hydrocarbons: Performance of various zeolite catalysts," Industriale Engineering Chemistry Research, vol. 38, no. 9, pp. 3230-3237, 1999.

[20] A. Budianto, D. H. Prajitno, A. Roesyadi, and K. Budhikarjono, "HZSM-5 catalyst for cracking palm oil to biodiesel: a comparative study with and without Pt and Pd impregnation," Chemistryer Chemical Engineering, Biotechnology, Food Industry, vol. 15, no. 1, pp. 081-090, 2014.

[21] S. P. Katikaneni, J. D. Adjaye, and N. N. Bakhshi, "Conversion of canola oil to various hydrocarbons over Pt/HZSM-5 bifunctional catalyst," Canadian Journal of Chemical Engineering, vol. 75, no. 2, pp. 391401, 1997.

[22] S. P. Katikaneni, J. D. Adjaye, and N. N. Bakhshi, "Catalytic conversion of canola oil to fuels and chemicals over various cracking catalysts," Canadian Journal of Chemical Engineering, vol. 73, no. 4, pp. 484497, 1995.

[23] W. Widayat, S. A. Saputro, E. M. Ginting, N. A. Annisa, and H. Satriadi, "Biofuel production by catalytic cracking method using Zn/HZSM-5 catalyst," ARPN Journal of Engineering and Applied Sciences, vol. 12, no. 22, pp. 6347-6351, 2017.

[24] X. Zhao, L. Wei, J. Julson, Q. Qiao, A. Dubey, and G. Anderson, "Catalytic cracking of non-edible sunflower oil over ZSM-5 for hydrocarbon bio-jet fuel," New Biotechnology, pp. 1-13, 2015.

[25] F. M. Dayrit, O. M. Buenafe, E. T. Chainani, I. S. de Vera, I. D. Dimzon, E. G. Gonzales, and J. R. Santos, "Standards for essential composition and quality factors of commercial virgin coconut oil and its differentiation from RBD coconut oil and copra oil," Pbilippine Journal of Science, vol. 136, no. 2, pp. 119-129, 2007.

[26] R. Sotelo-Boyas, Y. Liu, and T. Minowa. "Production of green diesel by hydrocracking of canola oil on $\mathrm{Ni}-\mathrm{Mo} / \gamma-\mathrm{Al}_{2} \mathrm{O}_{3}$ and Pt-Zeolitic based catalysts," in AlChE Annual Meeting, 2008, pp. 1-9.

[27] T. Degnan and C. Kennedy, "Impact of catalyst acid/metal balance in hydroisomerization of normal paraffins," American Institute of Chemical Engineers, vol. 39, no. 4, pp. 607-614, 1993.

[28] E. Rohmah, "Biogasoline from catalytic hydrocracking reaction of waste virgin cooking oil using Bayah natural zeolite," International Journal of Environment and Bioenergy, vol. 3, no. 3, pp. 201-209, 2012.

[29] J. Satyarthi, T. Chiranjeevi, D. Gokak, and P. Viswanathan, "An overview of catalytic conversion of vegetable oils/fats into middle distillates," Catalysis Science \& Technology, vol. 3, no. 1, pp. 70-80, 2013.

[30] L. Marlinda, M. Al-Muttaqii, A. Roesyadi, and D. H. Prajitno, "Production of biofuel by hydrocracking of cerbera manghas oil using Co-Ni/HZSM-5 catalyst: Effect of reaction temperature," Journal of Pure and Applied Chemistry Research, vol. 5, no. 3, pp. 189-195, 2016.

[31] B. Donnis, R. G. Egeberg, P. Blom, and K. G. Knudsen, "Hydroprocessing of bio-oils and oxygenates to hydrocarbons: Understanding the reaction routes," Topics in Catalysts, vol. 52, no. 3, pp. 229-240, 2009.

[32] P. Maki-Arvela, I. Kubickova, M. Snare, K. Eranen, and D. Y. Murzin, "Catalytic deoxygenation of fatty acids and their derivatives," Energy Fuels, vol. 21, pp. 30-41, 2007.

[33] H. Heriyanto, S. Murti, S. I. Heriyanti, I. Sholehah, and A. Rahmawati, "Synthesis of green diesel from waste cooking oil through hydrodeoxygenation technology with $\mathrm{NiMo} / \gamma-\mathrm{Al}_{2} \mathrm{O}_{3}$ catalysts," RSCE, vol. 156, pp. 1-6, 2018. 